\title{
Do we still need renal biopsy in lupus nephritis?
}

\author{
Ewa Haładyj ${ }^{1}$, Ricard Cervera ${ }^{2}$ \\ ${ }^{1}$ Department of Connective Tissue Diseases, National Institute of Geriatrics, Rheumatology and Rehabilitation, Warsaw, Poland \\ ${ }^{2}$ Department of Autoimmune Diseases, Hospital Clinic, Barcelona, Catalonia, Spain
}

\begin{abstract}
The natural course of systemic lupus erythematosus (SLE) is characterized by periods of disease activity and remissions. Prolonged disease activity results in cumulative organ damage. Lupus nephritis is one of the most common and devastating manifestations of SLE. In the era of changing therapy to less toxic regimens, some authors have stated that if mycophenolate mofetil can be used for the induction and maintenance treatment in all histological classes of lupus nephritis, renal biopsy can be omitted. This article aims to answer the question of what brings the bigger risk: renal biopsy or its abandonment.
\end{abstract}

Key words: lupus nephritis, renal biopsy, repeated renal biopsy.

\section{Introduction}

Lupus nephritis $(\mathrm{LN})$ is one of the most common and devastating manifestations of systemic lupus erythematosus (SLE), affecting over half of patients with this systemic disease. Lupus nephritis is characterized by inflammatory damage to nephrons during the SLE flare [1-3]. Not only distinct clinical pictures, but also variable relative proportions of normal nephrons, acute inflammatory lesions, and chronic damage in time can be seen in the same patient in different periods of time. Thus, heterogeneity of LN can be observed not only between patients but also between different periods of disease in the same patient. Nephron damage during acute inflammation in LN is rapid, but potentially reversible by adequate immunosuppressive treatment. Conversely, chronic lesions, such as fibrosis and tubular atrophy, do not improve with immunosuppressive treatment and result in chronic renal impairment [4].

For many years renal biopsy has remained the gold standard in the first approach to patients with suspected LN. In the American College of Rheumatology (ACR)/Systemic Lupus International Collaborative Clinics (SLICC) criteria for classification of SLE from 2012 [5], renal biopsy characteristic for LN together with a positive sample for antinuclear (ANA) or anti-dsDNA antibodies is sufficient for the SLE classification. But on the other hand, some experts start to doubt the necessity of renal biopsy in LN or postulate its limited usage. Facing in everyday practice all concerns of patients with this invasive, painful and frightening procedure, and the physicians' desire to avoid unnecessary harm and risk, the question "Do we still need renal biopsy?" arises.

\section{Renal biopsy in expert committees' recommendations}

The clinical and histopathological diversity of LN course is not helpful in finding the best possible algorithm in SLE management. A summary of available recommendations for renal biopsy is presented in Table I.

Experts recommend renal biopsy in all previously untreated patients with clinical evidence of active LN (unless strongly contraindicated). Biopsy should be performed before starting the immunosuppressive treatment, preferably within the first month after disease onset [6]. Renal biopsy allows specimens to be classified according to the current International Society of Nephrology/Renal Pathology Society (ISN/RPS) classification and to define activity and chronicity indexes for

Address for correspondence:

Ewa Haładyj, Department of Connective Tissue Diseases, National Institute of Geriatrics, Rheumatology and Rehabilitation, Spartańska 1, 02-637 Warsaw, Poland, e-mail: ehaladyj@o2.pl

Submitted: 17.03.2016; Accepted: 28.04.2016 
Table I. Indications for renal biopsy according to several committees' recommendations

\begin{tabular}{|c|c|c|c|c|}
\hline $\begin{array}{l}\text { Guideline } \\
\text { recommendation }\end{array}$ & $\begin{array}{l}\text { EULAR/ERA- } \\
\text { EDTA [6] }\end{array}$ & $\mathrm{ACR}[7]$ & SEMI-SEN [8] & $\begin{array}{l}\text { Dutch Working Party } \\
\text { on SLE [9] }\end{array}$ \\
\hline \multicolumn{5}{|l|}{ First renal biopsy } \\
\hline Proteinuria & $\begin{array}{l}\text { reproducible } \\
\text { proteinuria } \\
\geq 0.5 \mathrm{~g} / 24 \mathrm{~h}\end{array}$ & $\begin{array}{l}\text { confirmed proteinuria } \\
>1.0 \mathrm{~g} / 24 \mathrm{~h}\end{array}$ & $\begin{array}{l}\text { confirmed proteinuria } \\
>0.5 \mathrm{~g} / 24 \mathrm{~h}\end{array}$ & proteinuria $>0.5 \mathrm{~g} / 24 \mathrm{~h}$ \\
\hline $\begin{array}{l}\text { Active urine } \\
\text { sediment } \\
\text { (haematuria } \\
\text { and/or cellular } \\
\text { casts) }\end{array}$ & $\begin{array}{l}\text { may be } \\
\text { considered }\end{array}$ & yes & yes & no \\
\hline $\begin{array}{l}\text { Abnormal } \\
\text { renal function }\end{array}$ & $\begin{array}{l}\text { may be } \\
\text { considered }\end{array}$ & yes & yes & $\begin{array}{l}\text { - with persistent elevation of } \\
\text { serum creatinine }>30 \% \text { and } \\
\text { exclusion of other causes } \\
\text { of renal impairment; with } \\
\text { positive antiphospholipid } \\
\text { antibodies } \\
\text { - with extra-renal involvement/ } \\
\text { presence of anti-dsDNA } \\
\text { antibodies/low C3, C4 }\end{array}$ \\
\hline Other & & $\begin{array}{l}\text { - proteinuria } \\
\text { > } 0.5 \mathrm{~g} / 24 \mathrm{~h} \text { plus } \\
\text { haematuria } \\
\text { (> } 5 \mathrm{RBCs} \text { per } \mathrm{hpf}) \\
\text { - proteinuria } \\
\quad>0.5 \mathrm{~g} / 24 \mathrm{~h} \text { plus } \\
\text { - cellular casts }\end{array}$ & & \\
\hline \multicolumn{5}{|l|}{$\begin{array}{l}\text { Repeat renal } \\
\text { biopsy }\end{array}$} \\
\hline & $\begin{array}{l}\text { - worsening or } \\
\text { refractoriness to im- } \\
\text { munosuppressive or } \\
\text { biological treatment } \\
\text { (failure to decrease } \\
\text { proteinuria by } \geq \\
50 \% \text {, persistent } \\
\text { proteinuria beyond } \\
1 \text { year and/or wors- } \\
\text { ening of GFR) } \\
\text { - at relapse } \\
\text { - progression in histo- } \\
\text { logical class, change } \\
\text { in biopsy chronicity } \\
\text { and activity indices }\end{array}$ & $\begin{array}{l}\text { - no response to } \\
\text { treatment } \\
\text { - deteriorating renal } \\
\text { function }\end{array}$ & $\begin{array}{l}\text { - additional or increased } \\
\text { proteinuria, nephrotic } \\
\text { syndrome or active urine } \\
\text { sediment, especially if } \\
\text { the first biopsy was in } \\
\text { non-proliferative class } \\
\text { - Increased serum cre- } \\
\text { atinine or unexplained } \\
\text { evolution } \\
\text { - to kidney failure } \\
\text { - refractory to immuno- } \\
\text { suppressive treatment } \\
\text { - uncertainty about the } \\
\text { level of activity/chronic- } \\
\text { ity of renal damage in } \\
\text { therapeutic decisions } \\
\text { - suspected other ne- } \\
\text { phropathy }\end{array}$ & $\begin{array}{l}\text { - persistence of proteinuria } \\
\text { after reaching a partial re- } \\
\text { sponse, despite optimal } \\
\text { supportive treatment } \\
\text { including salt restriction } \\
\text { and treatment with ACEi or } \\
\text { ARBs } \\
\text { - failure to respond } \\
\text { (either complete or partial } \\
\text { response) at } 12 \text { months after } \\
\text { the start of the initial } \\
\text { induction treatment }\end{array}$ \\
\hline
\end{tabular}

tubular and vascular changes [10]. In 2003, the ISN/RPS proposed the current system of classifying renal biopsy [11]. Ten glomeruli as a minimum are required to perform credible examination and to exclude focal disease. The biopsy should be examined by light microscopy, immunofluorescence and, if possible, electron microscopy. Furthermore, vascular and interstitial lesions should be described and data on activity and chronicity should be quantified (but activity and chronicity indices are not obligatory).

However, common agreement on quantity of proteinuria, isolated active urine sediment or deterioration of renal function as indications for renal biopsy cannot be found. For the majority of experts, the most convincing 
item is proteinuria higher than $0.5 \mathrm{~g} / 24 \mathrm{~h}$ [6-9]. In patients with glomerular filtration rate (GFR) $<30 \mathrm{ml} / \mathrm{min}$ without significant proteinuria the decision for biopsy is doubtful, unless the kidney size is normal $(>9 \mathrm{~cm}$ length in adults) and/or there is evidence of renal disease activity according to the European League Against Rheumatism and European Renal Association-European Dialysis and Transplant Association (EULAR/ERA-EDTA) recommendations [6].

Indications for repeat renal biopsy are controversial and still differ between experts. Due to heterogeneity and variability of the clinical picture of $L N$ in time, the value of repeat renal biopsy in determining patients' prognosis is unknown. Most recommendations highlight selected indications such as worsening or refractoriness to treatment. Thus repeat renal biopsy provides important assistance in therapeutic decisions in patients with relapsing or refractory disease. It is also used in clinical trials to monitor treatment efficacy, and additionally can help to establish the role of changes in activity and chronicity scores in future prognosis.

\section{Renal biopsy at the beginning of symptoms}

In the majority of cases, the first feature of $L N$ is proteinuria of at least 500 to $1000 \mathrm{mg} / 24 \mathrm{~h}$, in the presence or absence of renal insufficiency or active urine sediment. Problems arise in patients not included in the guidelines mentioned above, with lower proteinuria than $500 \mathrm{mg} / 24 \mathrm{~h}$, who actually can present severe LN [12]. For example, within 38 SLE patients with glomerular hematuria with less than $500 \mathrm{mg} / 24 \mathrm{~h}$ proteinuria in the first renal biopsy, 95\% revealed class III, IV, or V LN, and only $5 \%$ had class $\|$ [13]. These data demonstrate that activity measurement in LN should not rely only on clinical and laboratory parameters without renal biopsy, because it can lead to incorrect therapeutic decisions.

Recently, clinical data support the opinion that mycophenolate mofetil (MMF) with glucocorticosteroids can become the first-line therapy instead of cyclophosphamide for all the serious forms of LN (class III, IV, and v) [14], thus making it possible to eliminate the need to differentiate between each histological class of $L N$ at the beginning of therapy. But this strategy has numerous insidious hazards. Proteinuria or active urine sediment in SLE can occur not only in LN. Patients may also develop other glomerular diseases, such as minimal change disease or focal segmental glomerulosclerosis, named lupus podocytopathies, but other disorders can also occur (e.g. thin basement membrane disease, amyloidosis, IgM nephropathy or tubular necrosis related to medications, hypovolemia, or hypotension) [15-18]. Lu- pus podocytopathies cannot be diagnosed without renal biopsy, because no laboratory markers or clinical symptoms can distinguish them from LN. In the treatment of lupus podocytopathies short courses of glucocorticosteroids alone are beneficial [19]. The incidence of glomerulonephritis other than LN was confirmed in 5\% in a series of more than 200 patients with SLE [16]. Clinical data such as serum creatinine, proteinuria or urine analysis are not sufficient for therapeutic decisions in LN, because their presence or absence is not strictly connected with activity or damage in LN. Predicting the extent of renal histologic activity or chronicity can be estimated only by renal biopsy [20, 21]. The activity and chronicity indexes allow one to assign patients to the group requiring immunosuppression or to another, where kidney-protective therapies are indicated (e.g. strict blood pressure control, sodium restriction, and inhibitors of the renin-angiotensin-aldosterone system) [22].

A common problem in SLE is accompanying antiphospholipid syndrome (APS) or the presence of antiphospholipid antibodies. The renal pathophysiological feature of this disease is glomerular thrombotic microangiopathy. It occurs in about $30 \%$ of patients with SLE, alone or in combination with LN [23-25]. Diagnosis of renal thrombotic microangiopathy without a biopsy is impossible, because the presence of antiphospholipid antibodies is not enough. Again, treatment with immunosuppression instead of the required anticoagulation in patients with APS is not efficient and may cause rapid deterioration of renal filtration [26].

\section{Early biopsy after the induction treatment}

Important information on the prognostic value of renal biopsy after the induction of treatment comes from studies that have been conducted for clinical indications and from protocol biopsy studies. Data from biopsies performed after 6 to 9 months of induction therapy in adults and children undergoing multiple treatment proved to be more predictive for long-term patient and kidney outcomes than the biopsy at diagnosis [27-29]. In the first renal biopsy before starting the therapy it is difficult to predict the histopathologic findings with long-term kidney function or response to therapy in the short term $[27,28]$. Thus, some authors have postulated that delaying renal biopsy until the end of induction treatment may be better for estimating patients' prognosis.

In adults, ongoing glomerular and interstitial inflammation, ongoing presence of glomerular capillary immune complexes and the presence of macrophages in tubular lumens at the 6-month biopsy was predictive 
for doubling of serum creatinine $[27,29]$. On the other hand, the extent of chronicity on the second biopsy did not predict long-term outcome. Other studies reported poor long-term outcomes such as doubling of serum creatinine, renal impairment, or death in patients with persistent glomerular and tubulo-interstitial inflammation, and persistence or worsening of subendothelial immune-complex deposits in repeat biopsy one year or more after induction therapy [26, 27, 30-33].

Response of the kidney to treatment can be shown in biopsies done directly after induction therapy. Generally a decline in active lesions with an increase in scarring lesions is observed [32]. At the moment, all the knowledge on the biopsy after the induction period does not reveal the impact of treatment decisions. The question of whether patients without active changes in the biopsy after induction treatment need maintenance immunosuppression remains unanswered [27, 32]. The demonstration from prospective trials supporting this hypothesis could lead to stopping maintenance treatment in this group of LN patients and become a strong indication for renal biopsy after the induction treatment period.

\section{Renal biopsy after maintenance treatment}

The current standard of care in LN after the induction treatment is maintenance therapy with MMF or azathioprine (AZA). Maintenance treatment should be administered for at least 3 years. In patients with residual disease or without clinical symptoms of active disease, the decision on withdrawing maintenance therapy should be made with maximum caution. It is impossible to determine whether these patients, who are otherwise doing well clinically, need a longer duration of maintenance therapy without performing renal biopsy. This dilemma is especially important in all patients considering pregnancy in the period immediately after withdrawal of maintenance treatment, when the risk of subsequent LN flare is high. LN activity, defined as the presence of subendothelial immune deposits, cellular/fibrocellular crescents, glomerular necrosis, or active interstitial nephritis and a National Institute of Health (NIH) activity index $>2$ [34], is the argument against stopping the treatment. The presence of ongoing subendothelial immune deposits and cellular crescents has the highest predictive value for long-term renal impairment [35, 36].

Repeat kidney biopsies at the end of the maintenance phase of $L N$ in patients who had clinically responded to the treatment can be planned to assess disease activity before discontinuing therapy. The rationale for performing these biopsies is the observation that
LN can still be active after several years of immunosuppression. In these patients, discontinuation of immunosuppressive therapy can lead to rapidly progressing chronic kidney injury. Even aggressive standard therapy of $L N$ and clinical response (early declines in proteinuria and creatinine concentrations) do not protect from chronic kidney lesions, which after initial accumulation during the first six months of therapy tends to plateau in further observations. It leads to the conclusion that in patients with ongoing but clinically silent histologic activity, stopping maintenance immunosuppression may predispose to $\mathrm{LN}$ relapses.

This conclusion can be strengthened by the fact that one-third of patients have continuous inflammatory lesions or subendothelial immune complexes despite complete clinical response. Meanwhile, over half of patients with residual low-level proteinuria (500-1000 $\mathrm{mg} / \mathrm{d}$ ) after years of therapy do not appear to have active, ongoing renal inflammation.

At the same time, some authors stated that after 6 months of treatment, persistent lesions in specimens from renal biopsy may be seen without ongoing systemic immune injury. According to this concept, resolution of the histological lesions of $L N$ is a slow process and immune deposits persist for several months in LN even in the absence of active disease [37]. Additionally, in 35\% of patients with complete clinical remission (proteinuria $<0.33 \mathrm{~g} / \mathrm{d}$, serum creatinine $<1.4 \mathrm{mg} / \mathrm{dl}$ ) moderate to severe renal flares still occur during the follow-up [38]. On the other hand, only $8 \%$ of them reached end-stage renal disease after more than 10 years without systematic repeat biopsy [39].

Repeat renal biopsy after the maintenance period not only help to distinguish patients with histopathological activity; it is also a good clinical argument to safely stop immunosuppression in patients with low-grade proteinuria. All these considerations create the need for a prospective study randomizing patients to continue or withdraw maintenance immunosuppression on the basis of a renal biopsy result.

To date, many studies on repeat biopsy have searched in renal histology for predictors

of clinical prognosis, but no conclusions can be drawn from them [32, 38-40]. Preliminary findings showed that complement components may be useful in predicting repeat biopsy activity. Very interesting results of a recent Argentinean study are concerned with the type of treatment used in induction and maintenance periods [41]. All previous reports comparing cyclophosphamide (CYC) induction with maintenance with AZA or MMF vs MMF alone in both phases showed that both strategies generally lower activity indexes to a similar extent [39, 40, 42, 43], but in the Argentinean study the 
combination of CYC-MMF or AZA was associated with a greater reduction in active lesions than the MMF-MMF regimen [41]. All these observations should be considered with factors influencing the heterogenic response due to ethnicity/race or treatment compliance.

\section{Repeat renal biopsy in a flare}

Repeat renal biopsy in a flare is included in almost all recommendations. Some studies have investigated its role in LN flares and in determining patients who are refractory/not responding to treatment [44-46]. The decision to repeat a biopsy at LN flare according to some reports should be based on the LN class from the initial biopsy [47]. This conclusion was stated on the basis of observations that switching from a proliferative lesion to a pure non-proliferative class is less common [47], while generally a class switch in LN is common [21, 47]. Non-proliferative II or V LN class diagnosed at baseline biopsy can benefit from a repeat biopsy, because these patients have a reasonable possibility to switch to a proliferative LN that may require more aggressive immunosuppression. Conversely, repeat renal biopsy for LN flares in patients with originally proliferative $L N$ are more likely to confirm ongoing or recurrent proliferative $L N$, which consequently does not bring any change in therapy [48].

\section{Summary}

The natural course of SLE is characterized by periods of disease activity and remissions. Prolonged disease activity due to inadequate treatment results in cumulative organ damage $[49,50]$. The role of renal biopsy - initial and subsequent in the history of every patient - can change the therapeutic approach to a more aggressive one or protect against drug toxicity in inactive patients. Although there is still a need for new randomized, prospective studies to confirm clinical observations, in daily practice initial and repeat renal biopsies remain an important and valuable tool. At the moment, all the literature data do not allow us to state that omitting the renal biopsy in the diagnostic and therapeutic routine brings more advantages than threats.

The authors declare no conflict of interest.

\section{References}

1. Sutton EJ, Davidson JE, Bruce IN. The systemic lupus international collaborating clinics (SLICC) damage index: a systematic literature review. Semin Arthritis Rheum 2013; 43: 352-361.

2. Lopez R, Davidson JE, Beeby MD, et al. Lupus disease activity and the risk of subsequent organ damage and mortality in a large lupus cohort. Rheumatology (Oxford) 2012; 51: 491498.

3. Danila MI, Pons-Estel GJ, Zhang J, et al. Renal damage is the most important predictor of mortality within the damage index: data from LUMINA LXIV, a multiethnic cohort. Rheumatology (Oxford) 2009; 48: 542-545.

4. Davidson A, Aranow C. Lupus nephritis: lessons from murine models. Nat Rev Rheumatol 2010; 6: 13-20.

5. Petri M, Orbai AM, Alarcón GS, et al. Derivation and validation of the Systemic Lupus International Collaborating Clinics classification criteria for systemic lupus erythematosus. Arthritis Rheum 2012; 64: 2677-2686.

6. Bertsias GK, Tektonidou M, Amoura Z, et al.; European League Against Rheumatism and European Renal Association-European Dialysis and Transplant Association. Joint European League Against Rheumatism and European Renal Association-European Dialysis and Transplant Association (EULAR/ERA-EDTA) recommendations for the management of adult and paediatric lupus nephritis. Ann Rheum Dis 2012; 71: 1771-1782.

7. Hahn BH, McMahon MA, Wilkinson A, et al.; American College of Rheumatology. American College of Rheumatology guidelines for screening, treatment, and management of lupus nephritis. Arthritis Care Res (Hoboken) 2012; 64: 797-808.

8. Ruiz Irastorza G, Espinosa G, Frutos MA, et al.; Spanish Society of Internal Medicine (SEMI); Spanish Society of Nephrology (SEN). Diagnosis and treatment of lupus nephritis. Consensus document from the systemic auto-immune disease group (GEAS) of the Spanish Society of Internal Medicine (SEMI) and Spanish Society of Nephrology (SEN). Nefrologia 2012; 32 Suppl 1: 1-35.

9. Van Tellingen A, Voskuyl AE, Vervloet MG, et al.; Dutch Working Party on Systemic Lupus Erythematosus. Dutch guidelines for diagnosis and therapy of proliferative lupus nephritis. Neth J Med 2012; 70: 199-207.

10. Markowitz GS, D'Agati VD. The ISN/RPS 2003 classification of lupus nephritis: an assessment at 3 years. Kidney Int 2007; 71: 491-495.

11. Weening JJ, D'Agati VD, Schwartz MM, et al. The classification of glomerulonephritis in systemic lupus erythematosus revisited. J Am Soc Nephrol 2004; 15: 241-250.

12. Christopher-Stine L, Siedner MJ, Lin J, et al. Renal biopsy in lupus patients with low levels of proteinuria. J Rheumatol 2007; 34: 332-335.

13. De Rosa M, Toblli J, De Rosa G, et al. Could proteinuria less than $500 \mathrm{mg} / \mathrm{d}$ be an actual indicator of lupus nephritis biopsy? J Am Soc Nephrol 2013 [Annual Meeting Abstracts: P0720].

14. Weening JJ, D'Agati VD, Schwartz MM, et al. The classification of glomerulonephritis in systemic lupus erythematosus revisited. J Am Soc Nephrol 2004; 15: 241-250.

15. Hebert LA, Sharma HM, Sedmak DD, et al. Unexpected renal biopsy findings in a febrile systemic lupus erythematosus patient with worsening renal function and heavy proteinuria. Am J Kidney Dis 1989; 13: 504-507.

16. Baranowska-Daca E, Choi YJ, Barrios R, et al. Non-lupus nephritides in patients with systemic lupus erythematosus: a comprehensive clinicopathologic study and review of the literature. Hum Pathol 2001; 32: 1125-1135. 
17. Kraft SW, Schwartz MM, Korbet SM, et al. Glomerular podocytopathy in patients with systemic lupus erythematosus. J Am Soc Nephrol 2005; 16: 175-179.

18. Mok CC, Cheung TT, Lo WH. Minimal mesangial lupus nephritis: a systematic review. Scand J Rheumatol 2010; 39: 181189.

19. Shea-Simonds P, Cairns TD, Roufosse C, et al. Lupus podocytopathy. Rheumatology (Oxford) 2009; 48: 1616-1618.

20. Wang GB, Xu ZJ, Liu HF, et al. Changes in pathological pattern and treatment regimens based on repeat renal biopsy in lupus nephritis. Chin Med J (Engl) 2012; 125: 2890-2894.

21. Lee HS, Mujais SK, Kasinath BS, et al. Course of renal pathology in patients with systemic lupus erythematosus. Am J Med 1984; 77: 612-620.

22. Parikh S, Hebert L, Rovin B. Protecting the kidneys in lupus nephritis. Int J Clin Rheumatol 2011; 6: 529-546.

23. Daugas E, Nochy D, Huong DL, et al. Antiphospholipid syndrome nephropathy in systemic lupus erythematosus. J Am Soc Nephrol 2002; 13: 42-52.

24. Tektonidou MG. Renal involvement in the antiphospholipid syndrome (APS)-APS nephropathy. Clin Rev Allergy Immuno 2009; 36: 131-140.

25. Tektonidou MG, Sotsiou F, Moutsopoulos HM. Antiphospholipid syndrome nephropathy in catastrophic, primary, and systemic lupus erythematosus-related APS. J Rheumatol 2008; 35: 1983-1988.

26. Parikh SV, Rovin BH. Antiphospholipid syndrome nephropathy: an insidious cause of progressive renal failure. In: Vasoocclusive disorders and kidney disease, Nachman PH, Clark WF, Derebail VK (eds.). Washington, DC: American Society of Nephrology; 2014; 13: 1-6.

27. Hill GS, Delahousse M, Nochy D, et al. Predictive power of the second renal biopsy in lupus nephritis: significance of macrophages. Kidney Int 2001; 59: 304-316.

28. Askenazi D, Myones B, Kamdar A, et al. Outcomes of children with proliferative lupus nephritis: the role of protocol renal biopsy. Pediatr Nephrol 2007; 22: 981-986.

29. Hill GS, Delahouse M, Nochy D, et al. A new morphologic index for the evaluation of renal biopsies in lupus nephritis. Kidney Int 2000; 58: 1160-1173.

30. Alsuwaida A, Husain S, Alghonaim M, et al. Strategy for second kidney biopsy in patients with lupus nephritis. Nephro Dial Transplant 2012; 27: 1472-1478.

31. Esdaile JM, Joseph L, Mackenzie T, et al. The pathogenesis and prognosis of lupus nephritis: information from repeat renal biopsy. Semin Arthritis Rheum 1993; 23: 135-148.

32. Gunnarsson I, Sundelin B, Heimburger M, et al. Repeated renal biopsy in proliferative lupus nephritis - predictive role of serum C1q and albuminuria. J Rheumatol 2002; 29: 693-699.

33. Austin HA 3rd, Muenz LR, Joyce KM, et al. Prognostic factors in lupus nephritis. Contribution of renal histologic data. Am J Med 1983; 75: 382-391.

34. Austin HA 3rd, Muenz LR, Joyce KM, et al. Diffuse proliferative lupus nephritis: Identification of specific pathologic features affecting renal outcome. Kidney Int 1984; 25: 689-695.

35. Esdaile JM, Joseph L, Mackenzie T, et al. The pathogenesis and prognosis of lupus nephritis: Information from repeat renal biopsy. Semin Arthritis Rheum 1993; 23: 135-148.
36. Moroni G, Pasquali S, Quaglini S, et al. Clinical and prognostic value of serial renal biopsies in lupus nephritis. Am J Kidney Dis 1999; 34: 530-539.

37. McRae M, Rousseau-Gagnon M, Philibert D, et al. The interpretation of repeat renal biopsies in patients with lupus nephritis. Rheumatology (Oxford) 2014; 53: 1151-1152.

38. Chen YE, Korbet SM, Katz RS, et al. Value of a complete or partial remission in severe lupus nephritis. Clin J Am Soc Nephrol 2008; 3: 46-53.

39. Grootscholten C, Bajema IM, Florquin S, et al. Treatment with cyclophosphamide delays the progression of chronic lesions more effectively than does treatment with azathioprine plus methylprednisolone in patients with proliferative lupus nephritis. Arthritis Rheum 2007; 56: 924-937.

40. Pillemer SR, Austin HA 3rd, Tsokos GC, Balow JE. Lupus nephritis: Association between serology and renal biopsy measures. J Rheumatol 1988; 15: 284-288.

41. Alvarado AS, Malvar A, Lococo B, et al. The value of repeat kidney biopsy in quiescent Argentinian lupus nephritis patients. Lupus 2014; 23: 840-847.

42. Ong LM, Hooi LS, Lim TO, et al. Randomized controlled trial of pulse intravenous cyclophosphamide versus mycophenolate mofetil in the induction therapy of proliferative lupus nephritis. Nephrology (Carlton) 2005; 10: 504-510.

43. Hu W, Liu Z, Chen H, et al. Mycophenolate mofetil vs cyclophosphamide therapy for patients with diffuse proliferative lupus nephritis. Chinese Med J 2002; 115: 705-709.

44. Moroni G, Pasquali S, Quaglini S, et al. Clinical and prognostic value of serial renal biopsies in lupus nephritis. Am J Kidney Dis 1999; 34: 530-539.

45. Alsuwaida A. The clinical significance of serial kidney biopsies in lupus nephritis. Mod Rheumatol 2014; 24: 453-456.

46. Norby GE, Strøm EH, Midtvedt K, et al. Recurrent lupus nephritis after kidney transplantation: a surveillance biopsy study. Ann Rheum Dis 2010; 69: 1484-1487.

47. Daleboudt GM, Bajema IM, Goemaere NN, et al. The clinical relevance of a repeat biopsy in lupus nephritis flares. Nephrol Dial Transplant 2009; 24: gfp359.

48. Parikh SV, Alvarado A, Malvar A, Rovin BH. The Kidney Biopsy in Lupus Nephritis: Past, Present, and Future. Semin Nephrol 2015; 35: 465-477.

49. Rabbani MA, Habib HB, Islam B, et al. Early renal damage assessed by the SLICC/ACR damage index is predictor of severe outcome in lupus patients in Pakistan. Lupus 2010; 19: 15731578.

50. Yap DY, Tang CS, Ma MK, et al. Survival analysis and causes of mortality in patients with lupus nephritis. Nephrol Dial Transplant 2012; 27: 3248-3254. 